\title{
Ensino de Imunologia na Educação Médica: Lições de Akira Kurosawa
}

\section{Teaching Immunology in Medical Education: Lessons from Akira Kurosawa}

\author{
Rodrigo Siqueira-Batista ${ }^{I}$ \\ Andréia Patrícia Gomes ${ }^{I I}$ \\ Verônica Santos Albuquerque ${ }^{\text {III }}$ \\ Rodrigo Madalon-Fragal \\ Ana Maria Coutinho Aleksandrowicz ${ }^{I V}$ \\ Mauro Geller
}

\section{PALAVRAS-CHAVE \\ - Imunologia. \\ - Educação médica. \\ - Modelo Imunológico.}

Recebido em: 14/04/2008

Reencaminhado: 15/06/2008

Aprovado: 18/06/2008

REVISTA BRASILEIRA DE EDUCAÇÃO MÉDICA
${ }^{I}$ Centro Universitário Serra dos Órgãos, Rio de Janeiro, Brasil; Centro Federal de Educação Tecnológica de Química de Nilópolis, Rio Janeiro, Brasil.

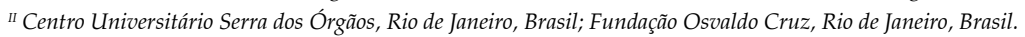

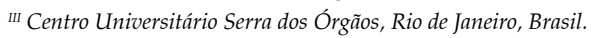

IV Fundação Osvaldo Cruz, Rio de Janeiro, Brasil.

O ensino e a investigação no campo da Imunologia se inscrevem, prevalentemente, num paradigma marcial - ou belicoso -, segundo o qual as interações hospedeiro-microrganismo são vistas de acordo com uma concepção de processos de ataque-defesa. Uma vez que este saber é tradicionalmente abordado nos cursos de graduação da área de saúde, tal perspectiva tem evidente influência na formação destes profissionais, incluídos os médicos. No presente artigo, reflete-se sobre as questões pedagógicas relativas ao modelo ataque-defesa. Realizou-se uma pesquisa teórica, utilizando-se o seguinte método: (1) revisão crítica da literatura, com textos obtidos nos livros e nos capítulos de livros de Imunologia; (2) leitura crítica dos textos; (3) elaboração de síntese reflexiva sobre o tema. Identificou-se que o modelo marcial da Imunologia se apresentou hegemônico nos livros-texto consultados, estando inscrito em idêntica concepção teórica inerente à medicina ocidental, ajudando a compor a visão dos estudantes dos cursos de graduação e pós-graduação e dos trabalhadores da área de saúde. É possível buscar alternativas, inclusive possibilidades para pensar a Imunologia em termos de novos modelos, em termos de homeostase e interdependência (ambos delimitando um paradigma ecológico), talvez mais propícios à abordagem das questões que ora se impõem nos seus horizontes, com inquestionáveis efeitos na educação.

Teaching and research in the field of Immunology adhere predominantly to a military or warlike paradigm, according to which the host-microorganism interactions are viewed from the perspective of attackand-defense processes. Since such knowledge is traditionally addressed in undergraduate health courses, this perspective has an obvious impact on the training of future health professionals, including physicians. The current article reflects on the pedagogical issues pertaining to the attack-and-defense model. A theoretical inquiry was conducted according to the following method: (1) critical review of the literature, with texts obtained from books and book chapters on Immunology; (2) critical reading of the texts; and (3) elaboration of a reflexive synthesis on the theme. The military model of Immunology is hegemonic in the textbooks, consistent with the identical theoretical concept that is inherent to Western medicine, helping condition the views of undergraduate and graduate students and future health professionals. It is possible to seek alternatives, including possibilities for conceiving Immunology in terms of new models, including homeostasis and interdependence (both shaping an ecological paradigm), potentially more amenable to an approach to the issues now on the horizon, with undeniable effects on medical education. 


\section{INTRODUÇÃO}

A ciência pode ser concebida como a atividade humana que tem na (tentativa de) descrição da realidade um dos aspectos cruciais do seu saber-fazer ${ }^{1}$. De fato, a atividade científica diz respeito ao

[...] conjunto de conhecimentos e de pesquisas com grau suficiente de unidade e generalidade, suscetíveis de levar [...] a conclusões concordantes que não resultam de convenções arbitrárias nem de gostos ou interesses individuais [...] mas, sim, de relações objetivas que se descobrem gradualmente e que se confirmam por métodos de verificação definidos. (p.278) ${ }^{2}$

Entre as diferentes perspectivas de concepção dos processos de construção histórica da ciência está a ideia de descontinuidades/rupturas entre suas teorias e seus métodos, como proposto por Thomas Kuhn no conceito de paradigma3 , âmbito no qual se consubstanciam "realizações científicas universalmente reconhecidas que, durante algum tempo, fornecem problemas e soluções modelares para uma comunidade de praticantes". (Kuhn $\left.{ }^{3} 2006\right)$

Nestes termos, o paradigma representa uma matriz disciplinar, composta por teorias, leis, técnicas e hipóteses, a qual subjaz à atividade de pesquisa científica, norteando-a e legitimando-a.

A Imunologia, como disciplina científica, tem se constituído em torno de um paradigma caracterizável como predominantemente "marcial", "belicoso" ou "beligerante", segundo o qual as interações hospedeiro-microrganismo são vistas segundo uma concepção de processos de ataque-defesa - ou seja, uma narrativa sobre a guerra inter e intraorganismos -, em que se estabelecem os termos de um discurso capazes de constituir uma genuína cosmovisão:

Os vocabulários nunca são neutros. As coisas que são incluídas em um vocabulário passam a compor uma realidade familiar; aquelas que são deixadas de fora são ignoradas ou chegam a ter a sua existência negada. Além disso, um vocabulário oferece uma versão de como o mundo funciona e por quê. (p. 70-71)

Tais ideias têm impacto nos âmbitos epistemológicos e pedagógicos da disciplina - como pontuado em investigação preliminar sobre o assunto $^{5}$-, com decisiva ingerência na formação médica ${ }^{6}$.
Com base nestas considerações, o presente artigo tem por escopo (1) apresentar o paradigma marcial da Imunologia a partir de sua identificação em livros-texto da disciplina; (2) discutir possíveis alternativas a este modelo; (3) pontuar as consequências destes debates sobre a formação médica.

\section{MÉTODOS}

Trata-se de uma pesquisa teórica apoiada na revisão crítica da literatura. A primeira etapa consistiu na busca de textos, utilizando-se a consulta a livros e a capítulos de livro de Imunologia. Busca complementar foi realizada nas seguintes bases: BVS - Biblioteca Virtual em Saúde; Pubmed - U. S. National Library of Medicine; e Scielo - Scientific Eletronic Library Online.

A segunda etapa consistiu na leitura dos manuscritos e na identificação de suas ideias centrais à luz da concepção de paradigma marcial.

Na terceira e última etapa, construiu-se uma síntese reflexiva sobre o tema, cujas conclusões são aplicáveis no âmbito da educação na área médica.

\section{RESULTADOS}

Foram consultados nove livros e dois capítulos de livros ${ }^{7-17}$.

Os textos da Imunologia estão, em grande medida, inscritos no paradigma marcial - ou belicoso -, como explicitado no Quadro 1.

As citações "falam por si mesmas": vive-se numa terrível guerra - cuja metáfora seria Ran de Kurosawa ${ }^{18}$-, vencida por aquele que dispuser das melhores armas: os "invasores" (em geral, microrganismos), eventualmente os "rebeldes" (como as células neoplásicas) ou os "invadidos" (habitualmente seres vivos multicelulares, incluído o Homo sapiens sapiens).

\section{DISCUSSÃO}

O modelo marcial da Imunologia é uma das manifestações de idêntica concepção teórica inerente à medicina ocidental - como, por exemplo, nas consagradas expressões propedêutica armada e arsenal terapêutico. Em última análise, representa uma leitura deveras empobrecida, pois reduz a diversidade e complexidade do sistema imunológico (SI) a simples relações causais, nas quais cabe ao hospedeiro tão-somente se proteger das bárbaras invasões (microbianas) ou das rebeliões internas (tumorais). Tal perspectiva acaba por infestar - para se manter no vocabulário vigente - a compreensão dos estudantes de Medicina, fazendo-os crer que microrganismos são inimigos que precisam ser vencidos por linfócitos e anticorpos - às vezes, com reforços dos antimicrobianos ${ }^{19}$-, genuínos soldados e armas. Trata-se, pois, de uma lídima metáfora bélica, com importantes consequências: 
QUADRO 1

Excertos de textos de Imunologia inscritos no paradigma marcial ${ }^{7-17}$

\begin{tabular}{|c|c|c|c|}
\hline Autor(es) & Ano & Livro-Texto & Trecho Selecionado \\
\hline \multicolumn{4}{|c|}{ LIVROS } \\
\hline Abbas e colaboradores ${ }^{7}$ & 2003 & Imunologia celular e molecular & $\begin{array}{l}\text { A imunidade inata proporciona as linhas iniciais de defesa } \\
\text { contra os microrganismos. }\end{array}$ \\
\hline Balestieri $^{8}$ & 2006 & Imunologia & $\begin{array}{l}\text { Se olharmos para o nosso corpo, também apresentamos } \\
\text { duas muralhas de proteção: a pele a as mucosas representa- } \\
\text { riam a primeira muralha, e o tecido abaixo da pele e das } \\
\text { mucosas, a segunda. }\end{array}$ \\
\hline Doan e colaboradores ${ }^{9}$ & 2006 & Imunologia médica essencial & $\begin{array}{l}\text { O sistema imunológico protege constantemente o indiví- } \\
\text { duo contra a invasão microbiana. Basicamente, existe um } \\
\text { constante estado de guerra entre os patógenos e o hospedeiro, e o } \\
\text { sistema imunológico é responsável pela defesa do corpo con- } \\
\text { tra a ameaça de ataque patogênico. }\end{array}$ \\
\hline Levinson e Jawetz ${ }^{10}$ & 2005 & Microbiologia médica e imunologia & $\begin{array}{l}\text { A principal função do sistema imunológico é prevenir ou } \\
\text { limitar infecções causadas por microrganismos como bac- } \\
\text { térias, vírus, fungos e parasitas. A primeira linha de defesa } \\
\text { contra os microrganismos é a pele intacta e as membranas } \\
\text { mucosas. Se os microrganismos romperem essa linha e en- } \\
\text { trarem no corpo, então o ramo inato do sistema imune está } \\
\text { disponível para destruir os invasores. }\end{array}$ \\
\hline Peakman e Vergani ${ }^{11}$ & 1999 & Imunologia básica e clínica & $\begin{array}{l}\text { Em biologia, o encargo é a doença - causada por uma va- } \\
\text { riedade de vírus, fungos, bactérias, protozoários, vermes e } \\
\text { toxinas -, e o papel fisiológico do sistema imune é mantê-los } \\
\text { em xeque. }\end{array}$ \\
\hline Roitt e colaboradores ${ }^{12}$ & 1999 & Imunologia & $\begin{array}{l}\text { Como a maioria dos organismos, em última análise, é des- } \\
\text { truída pelos fagócitos, não é de surpreender que estes orga- } \\
\text { nismos tenham desenvolvido um arsenal de mecanismos para se } \\
\text { contraporem a este risco. }\end{array}$ \\
\hline Roitt e Delves ${ }^{13}$ & 2004 & Fundamentos de imunologia & $\begin{array}{l}\text { A IgA aparece seletivamente nas secreções seromucosas, } \\
\text { como saliva, lágrimas, líquidos nasais, suor, colostro e se- } \\
\text { creções do pulmão, tratos genitourinário e gastrintestinal, } \\
\text { onde ela claramente possui o trabalho de defender as superfí- } \\
\text { cies externas expostas do organismo contra o ataque por micror- } \\
\text { ganismos. }\end{array}$ \\
\hline Sharon $^{14}$ & 2000 & Imunologia básica & $\begin{array}{l}\text { A relação entre o sistema imunológico e os patógenos ou } \\
\text { substâncias estranhas prejudiciais pode ser considerada } \\
\text { como uma guerra sem fim. }\end{array}$ \\
\hline Stites e colaboradores ${ }^{15}$ & 2000 & Imunologia médica & $\begin{array}{l}\text { Se algum patógeno (isto é, qualquer microrganismo com } \\
\text { o potencial de causar lesão tecidual ou doença) conseguir } \\
\text { abrir uma brecha no organismo, irá deparar-se com uma panóplia } \\
\text { de outros fatores que defendem os tecidos internos. }\end{array}$ \\
\hline \multicolumn{4}{|c|}{ CAPÍTULOS DE LIVROS } \\
\hline Goronzy e Weyand ${ }^{16}$ & 2005 & Cecil Tratado de medicina interna & $\begin{array}{l}\text { Se os microrganismos invasores conseguirem escapar dos } \\
\text { mecanismos de defesa, a imunidade adquirida garante a } \\
\text { sobrevivência do hospedeiro. As respostas imunológicas } \\
\text { adquiridas dependem da suplementação, da amplificação } \\
\text { e de informações cruciais quanto à natureza do agressor, pro- } \\
\text { porcionadas pela imunidade natural. }\end{array}$ \\
\hline Haynes e Fauci ${ }^{17}$ & 2002 & Harrison Medicina interna & $\begin{array}{l}\text { O sistema imune humano evoluiu durante milhões de anos } \\
\text { de organismos invertebrados e vertebrados para desenvol- } \\
\text { ver mecanismos de defesa sofisticados altamente específicos } \\
\text { contra patógenos invasores. }\end{array}$ \\
\hline
\end{tabular}


Metáforas podem criar realidades para nós, especialmente realidades sociais. Uma metáfora pode, então, ser um guia para ação futura. Tal ação, obviamente, corresponderá à metáfora. Isto, por sua vez, reforçará o poder da metáfora de tornar a experiência coerente. Neste sentido, as metáforas podem ser profecias que validam a si mesmas. ${ }^{20}$

Ao se validar a si mesma, a metáfora da guerra - constituinte do paradigma marcial - acaba por se tornar "real", perpetuando a inscrição no modelo, uma vez que estes estudantes, assim como os outros das áreas de saúde e de ciências biológicas, serão os imunologistas de amanhã.

Estará, então, a "guerra perdida"? Provavelmente não. De fato, a despeito deste panorama, há autores que questionam o modelo vigente:

Quando dizemos que o sistema imune nos defende, identificando e eliminando materiais estranhos, em meio aos componentes do corpo, estamos usando, deliberadamente ou não, uma metáfora. Não existe uma entidade inteligente planejando e desenvolvendo estratégias defensivas contra invasores antigênicos no meio do sistema imune. As modificações, que o sistema atravessa, surgem como decorrências inevitáveis de sua estrutura celular e molecular. Tais mudanças estruturais ocorrem como se o corpo se defendesse e, usualmente, resultam na eliminação de materiais estranhos sem causar danos excessivos à estrutura do organismo. Mas elas não derivam de um planejamento da defesa. A defesa não é intencional. ${ }^{21}$

A citação de Vaz e Faria ${ }^{21}$ traz apontamentos para se pensar novos modelos de compreensão do sistema imunológico a partir de concepções presentes na literatura desde a década de $1960^{22,23}$. Com efeito, esforços têm sido envidados na proposição de paradigmas alternativos, abrindo possibilidades para uma possível transição paradigmática na Imunologia ${ }^{24,25}$, cujos padrões de compreensão enfatizariam: (1) a imunidade concomitante $^{22,23}$; (2) o funcionamento em rede - por exemplo, no caso das sinapses imunológicas ${ }^{26,27}$; (3) a auto-organização ${ }^{28}$; (4) a homeostase $\mathrm{e}^{29}$; (5) as relações ecológicas ${ }^{30,31}$.

Esta transição paradigmática anunciada pode trazer reais implicações à educação médica, especialmente na vertente ecológica, na medida em que, de acordo com Capra ${ }^{32}$, é inerente à ecologia fazer perguntas profundas a respeito dos próprios fundamentos da cosmovisão vigente, questionando modelos com base num ponto de vista relacional: a partir da perspectiva dos relacionamentos de todos os seres com as gerações futuras e com a teia da vida da qual se é parte. Assim, pois, é admissível pensar que o ensino de Imunologia, tal qual o de outras ciências inter-relacionadas - Bacteriologia, Virologia, Micologia, Parasitologia, por exemplo -, sob a égide do paradigma ecológico, favoreceria uma formação mais integral e reflexiva, considerando a complexidade dos fenômenos estudados.

Nesse contexto, deve se ressaltar a possibilidade de ampliar a compreensão - e delinear possíveis respostas - de significativos desafios contemporâneos, como o surgimento de doenças emergentes e reemergentes, o desenvolvimento de resistência bacteriana aos antimicrobianos e a modulação de fatores de virulência.

\section{CONSIDERAÇÕES FINAIS}

A transição do paradigma marcial da Imunologia é não apenas pensável, mas também possível, podendo se obter indícios de que novos modelos já se encontram em gestação. De fato, paradigmas alternativos, de tessitura ecológica, nos quais é afirmada a complexidade das inter-relações entre os seres vivos, vêm ganhando espaço, ainda que de modo bastante preliminar, no âmbito da Imunologia. Nestas situações, a destruição de um ou de ambos os seres vivos relacionados ou sua convivência por anos a fio - observada, amiúde, nas infecções por Schistosoma mansoni e por Trypanosoma cruzi, por exemplo -, passariam a ser vistas como possibilidades dentre uma miríade de desenlaces possíveis.

Estas reflexões poderão contribuir para a elaboração e o ensino de modelos mais fecundos à compreensão dos sistemas vivos, contexto cujas implicações na educação médica são profundas. Esse novo horizonte - menos beligerante e talvez mais dirigido a entender a resposta imune como busca do equilíbrio perdido, algo que permeia Rapsódia em agosto, também de Kurosawa ${ }^{18}$-, será, provavelmente, mais propício à formação de médicos mais aptos à solvência dos diferentes problemas colocados no âmago da disciplina.

\section{REFERÊNCIAS}

1. Abbagnano N. Dicionário de filosofia. São Paulo: Martins Fontes; 2003.

2. Lalande A. Vocabulaire technique de philosophie. 11 ed. Paris: Presses Universitaires de France; 1972.

3. Kuhn T. A estrutura das revoluções científicas. SP: Perspectiva; 2006.

4. Callenbach E. O poder das palavras. In: Capra F. Alfabetização ecológica. São Paulo: Cultrix; 2006.

5. Siqueira-Batista R, Gomes AP. As invasões bárbaras: reflexões sobre o ensino de Imunologia. Rev Dig Edu Perm Saúde 2004; 1:241. 
6. Santos S. A integração do ciclo básico com o profissional no curso de graduação em medicina: uma resistência exemplar. Rio de Janeiro: Papel \& Virtual; 2005.

7. Abbas AK, Andrew H. Lichtman, Jordan S. Pober. Imunologia Celular e Molecular. 4 ed. Rio de Janeiro: Revinter; 2003.

8. Balestieri FMP. Imunologia. São Paulo: Manole; 2006.

9. Doan T, Melvold R, Waltenbaugh C. Imunologia médica essencial. Rio de Janeiro: Guanabara Koogan; 2006.

10. Levinson W, Jawetz E. Microbiologia médica e imunologia. Porto Alegre: Artmed; 2005.

11. Peakman M, Vergani D. Imunologia Básica e Clínica. Rio de Janeiro: Guanabara Koogan;, 1999.

12. Roitt I, Brostoff J, Male D. Imunologia. 5 ed. São Paulo: Manole; 1999.

13. Roitt IM, Delves PJ. Fundamentos de Imunologia. Rio de Janeiro: Guanabara Koogan; 2004.

14. Sharon J. Imunologia Básica. Rio de Janeiro: Guanabara Koogan; 2000.

15. Stites DP, Terr AL, Parslow TG. Imunologia médica. Rio de Janeiro: Guanabara Koogan, 2000.

16. Goronzy JJ, Weyand CM. Os sistemas imunológicos natural e adquirido. In: Goldman LG, Ausiello D. Cecil Tratado de medicina interna. Rio de Janeiro: Elsevier; 2005.

17. Haynes BF, Fauci AS. Introdução ao sistema imune. In: Braunwald E, Fauci AS, Kasper DL, Hauser SL, Longo DL, Jameson JL. Harrison medicina interna. Rio de Janeiro: McGraw Hill; 2002.

18. Siqueira-Batista R, Gomes AP. Ran ou Rapsódia em agosto? A transição paradigmática da imunologia e suas implicações na formação médica In: $45^{\circ}$ Congresso Brasileiro de Educação Médica, 2007, Uberlândia. Rev Bras Educ Med 2007; 31:773-774.

19. Siqueira-Batista R, Gomes AP. Antimicrobianos: guia prático. Rio de Janeiro: Rubio; 2005.

20. Lakoff G, Johnson M. Metaphors we live by. Chicago: University of Chicago Press; 1980.

21. Vaz NM, Faria AMC. Guia incompleto de imunobiologia. BH: Coopmed, 1993.

22. Gershon RK, Carter RL, Kondo K. On concomitant immunity in tumour-bearing hamsters. Nature 1967; 213:674.

23. Smithers SR, Doenhoff MJ. Schistosomiasis. In: Cohen S, Warren KS. Immunology of parasitic infections. $2^{\text {nd }}$ ed. London: Blackewell Scientific, 1982. p 527-607.

24. Aleksandrowicz AMC, Gomes AP, Santos SS, Esperidião Antonio V, Geller M, Siqueira-Batista R. Imunologia e formação médica In: é possível uma transição paradigmática na Imunologia? $44^{\circ}$ Congresso Brasileiro de Educação Médica, Gramado. Rev Bras Educ Med 2006; 30:524-525.

25. Siqueira-Batista R, Gomes AP, Geller M, Esperidião Antônio VE, Madalon-Fraga R, Aleksandrowicz AMC. Is it possible, in Immunology, a paradigmatic transition? In: 31 Meeting of the Brazilian Society for Immunology, Armação dos Búzios, 2006. São Paulo: Sociedade Brasileira de Imunologia; 2006, v. 1, p. 44.

26. Siqueira-Batista R, Geller M. Analogias entre o sistema imune e o sistema nervoso: o caso das sinapses imunológicas. SBI na Rede, v. 54, p. 2, 2006. Disponível em http:/ / www.sbi.org.br/sbinarede/SBInarede54/analogia.htm.

27. Siqueira-Batista R, De-Pina-Costa A, Pires-do-Prado HJ, Gomes AP, Esperidião Antônio V, Geller M. Organismo em "rede": o modelo das sinapses imunológicas In: II Jornada Científica da Baixada Fluminense, 2007, Nilópolis. Livro de Resumos da II JCBF; 2007. v. 1, p.73-73

28. Siqueira-Batista R, Aleksandrowicz AMC. The immune system: understanding by means of self-organization processes In: 31 Meeting of the Brazilian Society for Immunology, 2006. Armação dos Búzios: Abstracts - XXXI Meeting of the Brazilian Society for Immunology; 2006. p. 49.

29. Cunliffe J. Tissue homeostasis and immunity: more on models. Scand J Immunol 2006; 64:172-176..

30. Lenzi HL, Vannier-Santos MA. Interface parasito-hospedeiro: coabitologia - uma visão diferente do fenômeno parasitismo. In: Coura JR. Dinâmica das doenças infecciosas e parasitárias. Rio de Janeiro: Guanabara Koogan; 2005. p. 19-44

31. Madalon-Fraga R, Siqueira-Batista R, Gomes AP, Geller M, Pinto-Nunes NR, Pereira-Redondo S, Porto-Da-Luz CRD, Aleksandrowicz AMC. Paradigmatic transition in Immunology: an ecological vision. $13^{\text {th }}$ International Congress of Immunology. Rio de Janeiro, Brazil, Aug 21-25, 2007, p. 2582.

32. Capra F. A teia da vida: uma nova compreensão científica dos sistemas vivos. 6.ed. São. Paulo: Cultrix; 2001.

\section{CONTRIBUIÇÃO DOS AUTORES}

Rodrigo Siqueira-Batista concebeu, originalmente, o presente artigo. Ato contínuo, trabalhou, lado a lado, com Andréia Patrícia Gomes, Verônica Santos Albuquerque, Rodrigo Madalon-Fraga, Ana Maria Coutinho Aleksandrowicz e Mauro Geller para a preparação da versão final do texto.

\section{CONFLITO DE INTERESSES}

Declarou não haver

\section{ENDEREÇO PARA CORRESPONDÊNCIA}

Rodrigo Siqueira-Batista Instituto Federal de Educação, Ciência e Tecnologia do Rio de Janeiro.

Rua Lucio Tavares, 1045

Centro - Nilópolis

CEP.: $26530060 \mathrm{RJ}$

E-mail: rsiqueirabatista@terra.com.br 